\title{
Recomponer la identidad familiar de las víctimas del franquismo más allá de la fosa común"
}

\author{
Frankismoaren biktimen familia-nortasuna osatzea hobi komunetik harago \\ Reassembling the Familial Identity of Victims of Francoist Repression \\ beyond the Mass Grave
}

\author{
Zahira Aragüüete-Toribio \\ Universidad de Ginebra (Suiza) \\ Zahira.AragueteToribio@unige.ch \\ https://orcid.org/0000-0002-8665-8174
}

Recibido / Noiz jaso den: 04/05/2021

Aceptado / Noiz onartu den: 22/05/2021

\begin{abstract}
Resumen
La búsqueda de los cadáveres de las víctimas de la represión extrajudicial franquista ha permitido en los últimos años la exhumación e identificación científica de miles de cuerpos enterrados en fosas comunes. Para algunas familias que no consiguen localizar los restos de sus familiares represaliados, sin embargo, los procesos de exhumación se convierten en espacios desde los que articular una historia familiar inconclusa. En este artículo analizamos cómo la búsqueda frustrada del cuerpo genera otras pesquisas familiares infatigables con el fin de evidenciar la vida y muerte del familiar desaparecido. Basándonos en los resultados de la investigación antropológica realizada durante una campaña de exhumación en Extremadura en 2011, argüimos que estas búsquedas dan pie a nuevos archivos familiares desde los que los descendientes dan sentido a una biografía fragmentada. El trabajo concluye que otras formas íntimas de identificación y reconocimiento del familiar tienen lugar en estos archivos compuestos por los rastros antagónicos que dejó la represión franquista.
\end{abstract}

\section{Palabras clave}

Exhumaciones; represión franquista; silencio; archivo familiar; posmemoria.

\section{Sumario}

1. INTRODUCCIÓN. 2. CONTAR LA REPRESIÓN DESDE LA FOSA COMÚN. 3. EMPRENDER LA BÚSQUEDA, APREHENDER LA AUSENCIA. 4. RECOMPONER LA IDENTIDAD DE LA PERSONA REPRESALIADA EN EL ARCHIVO FAMILIAR. 5. CONCLUSIONES. 6. BiBLIOGRAFíA.

* Este trabajo no hubiese sido posible sin la colaboración de Aurora Navas Morillo, quien, de manera generosa y amable compartió la dolorosa historia de su familia con nosotras, años antes de morir. Agradecemos también la invitación de AMECADEC a participar en la campaña de exhumación llevada a cabo en Castuera en 2011 y la valiosa ayuda y colaboración de Laura Muñoz Encinar en el desarrollo de este estudio etnográfico. Este artículo ha sido realizado en el marco del proyecto de investigación Right to Truth, Truth(s) through Rights: Mass Crimes Impunity and Transitional Justice, dirigido por Sévane Garibian en la Facultad de Derecho de la Universidad de Ginebra y financiado por el Fondo Nacional Suizo para la Investigación Científica (FNS) (proyecto FNS PP00P1_157406/1): http://right-truth-impunity.ch. 


\begin{abstract}
Laburpena. Errepresio frankista estrajudizialaren biktimen hilotzak bilatuta, hobi komunetan lurperatutako milaka gorpuzki atera eta identifikatu dira zientifikoki azken urteotan. Familia batzuek, ordea, ez dituzte aurkitu senitarteko errepresaliatuen gorpuzkiak. Horrelako kasuetan, exhumazio prozesuak historia familiar bukatugabeak osatzeko abagune bihurtzen dira. Artikulu honen aztergaia da senitartekoen gorpuzkien bilaketa antzua suertatzen denean nola aritzen diren familiakoak nekaezin ikertzen desagertutako senitartekoaren bizitza eta heriotza agerian uzteko. 2011n Extremaduran egindako exhumazio kanpaina bateko ikerketa antropologiko baten emaitzetan oinarrituta, artikulu honen idazleok argudiatzen dugu halako bilaketek artxibo familiar berriak ekartzen dituztela berekin, eta, horien bidez, ondorengoek zentzua ematen diotela biografia zatitu bati. Azkenik, artikuluan diogu errepresio frankistak utzitako arrasto antagonikoez osatutako artxibo horietan beste modu kutun batzuetan identifikatzen eta ezagutzen direla senitartekoak.
\end{abstract}

Gako hitzak. Exhumazioak; errepresio frankista; isiltasuna; artxibo familiarra; posmemoria.

\begin{abstract}
The search for the human remains of victims of Francoist extrajudicial repression has led, in the last years, to the scientific exhumation and identification of thousands of bodies buried in mass graves. For some families who are unable locate the human remains of their executed relatives, however, exhumations have also become spaces in which to enunciate an incomplete family history. This article explores how the unsuccessful search for the body of the victim triggers relentless family inquiries with the aim to evince the life and death of a disappeared family member. Drawing on the results of the anthropological study carried out at an exhumation campaign in Extremadura, in 2011, it argues that these quests have given place to new family archives through which descendants make sense of a fragmented biography. The paper concludes that, in so doing, other intimate forms of identification and recognition of the disappeared relative take place at the heart of an archive often composed by the antagonistic traces that remain of Francoist repression.
\end{abstract}

Keywords. Exhumations; Francoist repression; silence; family archive; postmemory.

\section{En memoria de Aurora Navas Morillo}

\section{Introducción}

La búsqueda, localización y exhumación de fosas comunes de víctimas de la represión franquista ha aportado nuevos indicios sobre el paradero de cientos de militantes y simpatizantes de izquierda, desaparecidos y ejecutados extrajudicialmente durante la Guerra Civil española y la más inmediata posguerra. Desde el año 2000, diferentes grupos de la sociedad civil que conforman el llamado movimiento para la recuperación de la memoria histórica han exigido al Estado español el esclarecimiento de la desaparición y muerte de las más de 114000 personas que todavía hoy permanecen enterradas en fosas ${ }^{1}$ y la recuperación y «digna

1 Esta cifra se basa en los datos proporcionados por el Juez Baltasar Garzón en su Auto de 16 de octubre de 2008. En su investiǵación judicial, el Juez Garzón contabilizó hasta 114266 casos en- 
sepultura» de sus restos. Tras años de silencio en torno a las ejecuciones y ante el efecto continuo de medidas como la Ley de Amnistía de 1977, la cual ha supuesto la falta de implicación estatal y judicial en la investigación de estos sucesos hasta la fecha, dichos colectivos - con la creciente ayuda de algunos gobiernos regionales- han abierto una nueva vía al entendimiento de la violencia franquista. Por una parte, las campañas de exhumación han tenido como objetivo primordial la labor humanitaria de restituir los restos de los ejecutados a sus familiares. Junto a ello, más allá de esta función, estas investigaciones desarrolladas fuera del marco judicial han servido para producir nuevas evidencias con el propósito de facilitar futuros procesos penales, promover un relato histórico alternativo y posibilitar la reconstrucción de una memoria familiar quebrantada por el impacto de una muerte violenta o una desaparición forzada.

Los procesos de exhumación han dado respuesta a una demanda familiar y social, que ha devuelto el rastro de los vencidos, tanto al espacio íntimo familiar como a la vida pública del país. Según estudios recientes, la colaboración entre activistas, familiares y profesionales del ámbito de la medicina forense, la arqueología, la antropología física, la historia o las ciencias sociales, entre otras disciplinas, ha hecho posible la exhumación de más de 740 fosas comunes y la recuperación de más de 9000 cuerpos en los últimos años ${ }^{2}$. Recomponer este pasado traumático, sin embargo, no ha sido tarea fácil. La mayoría de los documentos oficiales necesarios para aclarar la suerte de las personas ejecutadas extrajudicialmente durante la guerra y la posguerra, se caracterizan por las omisiones, distorsiones y argucias de las que la burocracia represiva franquista se sirvió a la hora de registrar las ejecuciones. Alguunos de estos documentos siguen siendo hoy inabordables, debido a la ausencia de una política de archivos estatal que facilite el acceso a muchas de las colecciones oficiales y privadas diseminadas a lo largo del país. De igual manera, el paso del tiempo ha dificultado la recogida de muchos testimonios directos e indirectos de las masacres, impidiendo conocer la ubicación de numerosas fosas comunes y la posible identificación de los cuerpos. A ello tendríamos que sumar que la localización y excavación de algunas fosas ha sido complicada debido a que, en ocasiones, se encuentran en lugares de difícil acceso décadas después de las ejecuciones.

Así, en muchos casos, el diálogo entre el conocimiento científico y el saber compartido por las personas que sufrieron la violencia franquista no siempre

tre el 17 de julio de 1936 y diciembre de 1951 (ver Ferrándiz, 2014, p. 212). Francisco Ferrándiz también observa que algunos estudios históricos recientes como el de Rodrigo, 2008, sitúan el número de represaliados extrajudicialmente en la retaguardia del ejército sublevado en más de 150000 personas (Ferrándiz, 2014, pp. 20-21).

2 Etxeberría y Solé, 2019. 
ha sido suficiente para obtener resultados que permitan la localización y recuperación de los restos de los represaliados. La búsqueda fallida ${ }^{3}$ de los cuerpos constituye otra manifestación de una estrategia represiva de largo alcance, cuyas consecuencias se materializan mediante la ausencia irreversible del cadáver de la víctima. Así lo pudimos constatar durante el período de trabajo de campo desarrollado en la región de Extremadura entre 2010 y 2012. Durante esta etapa, realizamos el seguimiento antropológico de hasta cuatro proyectos de localización y excavación de fosas, trabajando estrechamente con equipos arqueológicos y forenses, asociaciones de memoria histórica y decenas de familiares descendientes de las víctimas represaliadas. Esto nos permitió observar y colaborar en el trabajo científico realizado en el interior de las fosas y documentar las dinámicas sociales que se generan en el entorno de la exhumación. Además, a través de la recogida de testimonios, nuestra participación en estas campañas nos facilitó el acercamiento a historias familiares de desaparición a menudo soterradas por el silencio.

En este artículo abordamos, desde la antropología social, cómo la búsqueda frustrada de las personas desaparecidas y represaliadas por el franquismo afecta a la relación que centenares de familias establecen con una historia de violencia inconclusa. Para ello, nos centramos en el análisis de la experiencia de Aurora Navas Morillo, una mujer procedente de Castuera (Extremadura), quien tras muchos esfuerzos nunca loǵró encontrar los restos del cadáver de su madre, Matilde. Tomando como punto de partida la campaña de prospección y excavación de fosas llevada a cabo en la localidad de Castuera en 2011, analizamos cómo el proceso de exhumación se erige como un escenario desde el que dar sentido a un relato familiar a pesar de las lagunas existentes en torno al paradero de la persona represaliada. Argúuimos que las exhumaciones también dan pie a otros modos de evidenciar la vida y muerte de un familiar desaparecido, a través de formas íntimas de recomponer la identidad de las víctimas de la violencia franquista que se dan entre el espacio de la fosa común, el archivo oficial y el elenco personal de documentos, objetos y recuerdos reunidos mediante incansables pesquisas familiares. Estas biografías e historias de vida incompletas que reaparecen en el contexto de la exhumación se han convertido, además, en fraǵmentos desde los que articular un relato histórico alternativo sobre la represión franquista en la esfera pública del país.

3 Para una mirada más amplia sobre el fenómeno de las exhumaciones fallidas en otros contextos internacionales, consultar el número especial publicado recientemente por Delacroix y Losonczy, 2021. 


\section{Contar la represión desde la fosa común}

En el verano de 2011, un equipo científico compuesto por técnicos arqueólogos y estudiantes voluntarios de la Universidad de Extremadura y dirigido por la arqueóloga y antropóloga física Laura Muñoz Encinar se desplazó a la localidad de Castuera, al sureste de la región extremeña, para excavar el contenido de dos fosas comunes localizadas en el cementerio del pueblo. El proyecto de exhumación, promovido por la Asociación Memorial Campo de Concentración de Castuera (AMECADEC) y financiado por una de las subvenciones concedidas por el Ministerio de la Presidencia entre 2006 y 2011, era el resultado de un largó esfuerzo por localizar los cuerpos de las personas ejecutadas extrajudicialmente en la zona durante diferentes períodos ligados al desarrollo del conflicto. Por una parte, la asociación, que aglutinaba en ese momento tanto a historiadores y activistas políticos como a familiares de represaliados procedentes de la comarca, había trabajado durante años para desentrañar el paradero de las víctimas ejecutadas irregularmente tras la ocupación del pueblo por las tropas sublevadas en el verano de 1938. Por otra, se pretendía arrojar luz sobre el destino final de las personas desaparecidas tras proclamarse el final de la guerra y la victoria franquista en abril de 1939. Entre estos casos, se encontraban los detenidos a su regreso al pueblo tras el final de la contienda y los cientos de combatientes capturados tras la caída del frente extremeño. Muchos fueron trasladados al campo de concentración edificado a cuatro kilómetros de Castuera, con el fin de ser reubicados posteriormente a otros centros penitenciarios y batallones de trabajo ${ }^{4}$. Otros fueron eliminados selectivamente.

Antes del inicio de la campaña de excavación, el estudio de diferentes fuentes documentales había revelado la posible existencia de fosas comunes asociadas a los primeros momentos tras la finalización del conflicto en la zona trasera del cementerio. Concretamente, la investigación realizada a lo largo de la primera década del 2000 por el historiador Antonio López Rodríguez relacionaba dicha área con el funcionamiento del campo de concentración, activo entre marzo de 1939 y marzo de 1940. El análisis exhaustivo de la limitada y dispersa documentación existente en los principales archivos de la represión franquista, junto a la recogida de testimonios, proporcionaron al historiador diferentes detalles sobre la actividad represiva en el Campo y sus alrededores. La información contenida en los registros oficiales constataba, por un lado, la existencia de un Tribunal Provisional presidido por el jefe del Campo que se encargó de supervisar las labores de clasificación y el traslado de reclusos. Este cargoo, además, gestionaba el «cumplimiento de condenas» y los procesos sumarísimos impuestos por los

4 López Rodríguez, 2006; León Cáceres, López Rodríguez y González Cortés, 2011. 
juzgados militares habilitados en la zona ${ }^{5}$. Más allá de la actividad documentada en los archivos del Campo, algunas entrevistas con exǵuardianes y exprisioneros del centro de reclusión, confirmaban el desarrollo paralelo de un plan represivo ${ }^{6}$ mediante el cual se ejecutaría extrajudicialmente a decenas de prisioneros del complejo carcelario. La información de dichos testimonios, por otra parte, complementaba las declaraciones de algunos vecinos de Castuera, quienes aseguraban haber visto zanjas abiertas y cubiertas de manera apresurada de un día para otro en el camino que comunicaba el Campo con las traseras del cementerio. Esto sugería la presencia de enterramientos clandestinos relacionados con la actividad del campo de concentración y de la Prisión de Partido de la localidad ${ }^{7}$.

La aparición de diversos cráneos y suelas, así como «monedas, restos de tejido y una cremallera, una cantimplora, una bala y casquillos de pistola $»^{8}$ durante la prospección arqueológica del terreno en enero de 2011, aseveraba la hipótesis de que esta era una de las áreas en las que se ejecutaba a reclusos del campo de concentración. A lo largó del proceso de excavación, el uso de metodologías forenses aplicadas al análisis de los restos -todos ellos de hombres- y de los objetos encontrados en la primera fosa, llamada Fosa 1, pudo esclarecer la relación existente entre el primer enterramiento y el espacio represivo del campo de prisioneros. Por otra parte, la excavación científica de una segunda fosa, denominada como Fosa 3, mostraba una etapa represiva posterior, relacionada con la ejecución de tres guerrilleros en 1943. No obstante, a pesar de poder precisar algunos datos sobre el origen de los enterramientos, el carácter de la represión extrajudicial en Castuera dejaba abiertos interrogantes acerca de la identidad de las víctimas. Diversos estudios históricos coinciden en que la violencia golpista implantó diferentes estrategias represivas mediante las que se impuso de forma implacable el miedo y el silencio a las familias de los represaliados, ocasionando un gran vacío en torno al recuerdo de los desaparecidos y las víctimas de la localidad ${ }^{9}$. A esta afonía de relatos tenemos que sumar la inexistencia de un registro documental que refleje el censo oficial de las bajas que se estaban produciendo extrajudicialmente, tanto en el Campo como en la Prisión Central. Un silencio documental que se extiende al libro del cementerio y el registro civil de la localidad, haciendo aún más difícil la identificación genética de los restos exhumados en ambas fosas.

5 López Rodríguez, 2013, p. 41.

6 López Rodríguez, 2013, p. 50.

7 López Rodríguez, 2006; López Rodríguez, 2013.

8 Muñoz Encinar, 2013, p. 64.

9 López Rodríguez, 2006; León Cáceres, López Rodríguez y González Cortés, 2011; López Rodríguez, 2013. 


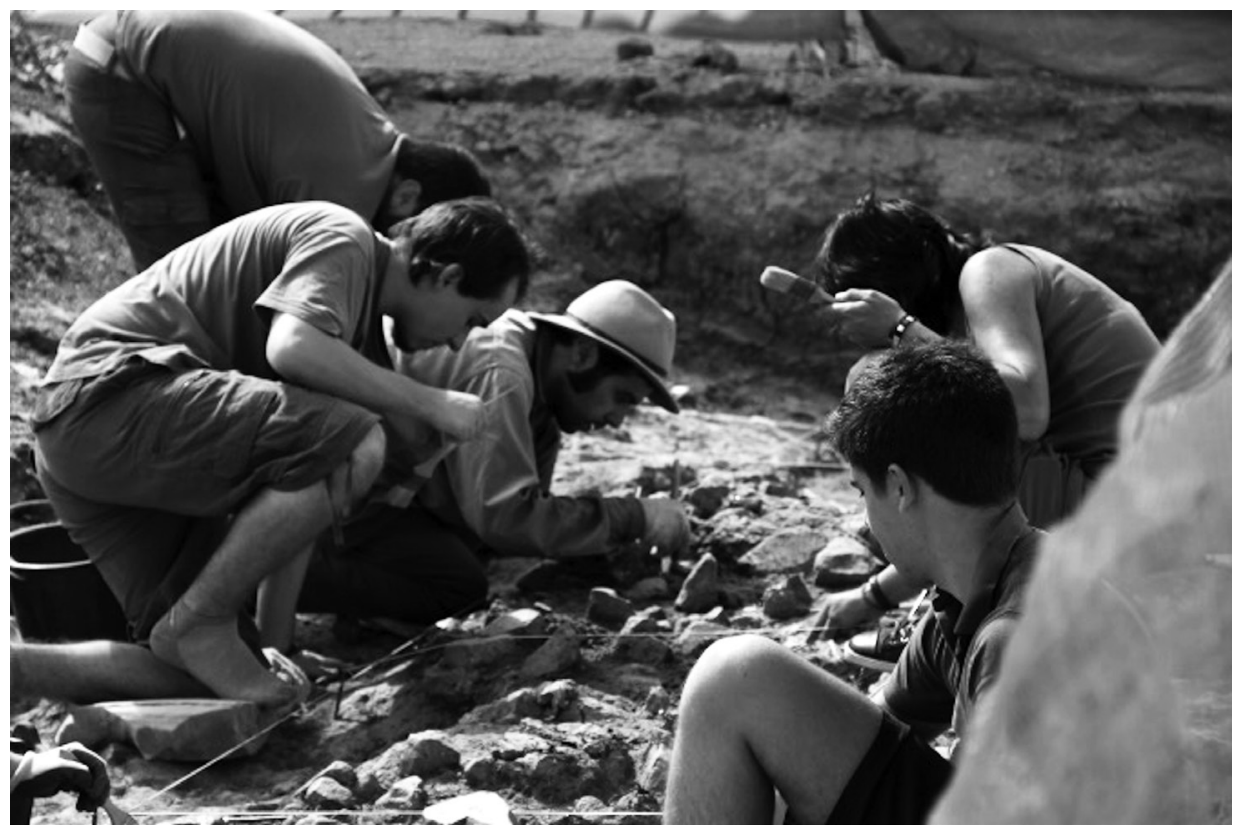

Figura 1. Un grupo de arqueólogos y voluntarios trabajan en las fosas de Castuera, 2011. Imagen de la autora.

La incertidumbre en torno a la procedencia de estos cadáveres abría así otros horizontes de esperanza para las familias que visitaban la excavación a diario con el fin de obtener respuestas sobre el destino final de sus desaparecidos. Para algunos miembros de la asociación, quienes, durante años, habían buscado sin suerte a sus familiares, vistos por última vez con vida en el campo de concentración o en la Prisión de Partido de Castuera, la labor de la exhumación suponía, pese a todo impedimento, una oportunidad de resolver las incógnitas que rodeaban su paradero. Los restos excavados se convertían así en el foco de las conversaciones entre familiares y científicos forenses. La imagen de los esqueletos enterrados atados en pareja por los brazos y muñecas con alambres o la presencia de restos de munición en la fosa concretizaba una realidad que hasta ahora solo había existido de forma imprecisa en los relatos desdibujados que circulaban sobre las ejecuciones. Asimismo, la variedad de objetos personales asociados a los individuos de la Fosa 1 invitaba a algunas familias a rememorar los itinerarios represivos sufridos por sus allegados, intentando establecer una correspondencia entre su relato y aquel que parecía emanar de la materialidad de la fosa. Algunos objetos despertaban el recuerdo de los efectos personales que la víctima llevaba consigo en el momento de su desaparición. Otros alentaban la reminiscencia de detalles específicos asociados al momento de la ejecución. Unas botas iguales a las calza- 
das por un familiar en su única fotografía, un lápiz que insinuaba la afición artística de su dueño o unos anteojos que recordaban aquellos utilizados por un padre se antojaban huellas a través de las que poder evocar el posible reencuentro con el familiar represaliado.

Algunos estudios sobre exhumaciones en contextos posbélicos contemporáneos alrededor del mundo han constatado el valor que los objetos personales adquieren como rastros que estimulan el recuerdo de la persona desaparecida durante los procesos científicos de recuperación e identificación. La antropóloga Sarah E. Waǵner explica que los materiales rescatados durante las campañas de exhumación llevadas a cabo tras la masacre de Srebrenica en Bosnia-Herzegovina constituyeron un soporte imprescindible para determinar la identidad de los más de 8000 hombres y niños bosnio-musulmanes que perdieron la vida a manos de fuerzas serbiobosnias en la región. En palabras de uno de los científicos forenses encargados de dicha tarea, los objetos de las personas ejecutadas «encarnan las vidas de los desaparecidos, sus historias personales y sus relaciones familiares, su fe, y el conocimiento que tenían sobre sus circunstancias en sus últimos días de vida ${ }^{10}$. Objetos como la vestimenta y otras posesiones encontradas en las fosas excavadas servían al forense como una hoja de ruta a la hora de navegar «el conocimiento íntimo» de las víctimas aportado por los familiares. Si bien, en este y otros casos, los objetos personales son un indicio importante para realizar una aproximación inicial a la identidad de la persona ejecutada, estos forman parte de un proceso más complejo de identificación científica que incluye el análisis de otros datos ante mortem asociados a la víctima, su comparación con la evidencia obtenida del estudio pos mortem de los restos y la realización de pruebas genéticas que confirmen la relación entre «la muestra esquelética» y el familiar solicitante ${ }^{11}$. Ante un objeto reconocido, las familias a las que Wagner entrevista a menudo invocaban la imagen de la persona antes de morir, los detalles intrínsecos de su ropa y el significado particular de cada una de sus pertenencias. En estos casos, el recuerdo familiar de la víctima evocado a través del objeto se convierte en una prueba irrefutable de su muerte y de la identidad del cadáver recuperado ${ }^{12}$.

En Castuera, a falta de información que permitiese al equipo científico establecer una conexión entre los cadáveres localizados en las fosas comunes y los represaliados identificados en la zona a través de investigaciones como las de Antonio López Rodríguez y otros historiadores, los hallazgoos de las Fosas 1 y 3 se convirtieron en materia para la imaginación. Para algunas de las familias asistentes a la exhumación, los objetos asociados a los restos serán un detonante para narrar

\footnotetext{
${ }^{10}$ Wagnner, 2008, p. 142.

${ }^{11}$ Ríos, 2012, p. 134.

12 Waǵner, 2008, p. 145.
} 
la vida de sus familiares represaliados, esbozar sus rasgos y personalidades y reflexionar sobre los eventos que habían marcado sus últimos momentos de vida. A través de la presencia de estos restos aun sin identidad, el entorno de la fosa se transformó en un escenario desde el que articular una historia personal, marcada por las secuelas del crimen y su impunidad. Dichas historias también evocaban las inagotables búsquedas familiares emprendidas para averiguar nuevos indicios sobre el destino final de la persona desaparecida. Algunos descendientes en Castuera comenzaron sus pesquisas décadas antes, durante los años de la dictadura, al sospechar por primera vez los hechos trágicos que acontecieron a la familia. Esta búsqueda se intensificó como consecuencia del ciclo de exhumaciones científicas iniciado tras la excavación de la fosa de Priaranza del Bierzo, en León, en el año 2000, la cual generó un movimiento social sin precedentes en torno a los represaliados del franquismo ${ }^{13}$. Interpeladas por la posibilidad de localizar los cuerpos sin vida de sus allegados, alǵunas familias emprendieron un recorrido extraordinario que las llevó a navegar los entresijos de una historia familiar fragmentada. En su intento, muchas redibujaron los contornos de identidades desvaídas y el trazo velado de un vínculo afectivo con la persona desaparecida.

\section{Emprender la búsqueda, aprehender la ausencia}

Entre las personas que visitaban con asiduidad el lugar de la exhumación en el cementerio de Castuera estaba Aurora Navas Morillo, una mujer de la localidad con una historia familiar marcada por la violencia que sacudió el pueblo tras el final de la contienda. La madre de Aurora, Matilde Morillo Sánchez, fue una de las personas asesinadas en la primavera de 1939, al volver a Castuera desde Damiel, el pueblo en la región de Castilla-La Mancha en el que Matilde había trabajado como maestra desde 1937. Matilde estaba casada con Antonio Navas Lora, un importante cargoo del Partido Socialista regional y miembro de la Unión General de Trabajadores del pueblo y de la provincia. Matilde y Antonio tuvieron cuatro hijas, entre ellas, Aurora y compartían, según explicaba ésta última, un deseo común de mejorar el acceso a la educación de los trabajadores y sobre todo de las mujeres en la empobrecida Extremadura de la época. En 1937, mientras Matilde comenzaba un nuevo empleo en Daimiel, Antonio combatía la guerra primero en Extremadura y más tarde en el levante español. Durante los últimos días del conflicto y ante la amenaza de represalias por parte de los sublevados, Antonio propuso a Matilde exiliarse a otro país junto con su hija más pequeña. Según contaba Aurora en una de las entrevistas realizadas durante la exhumación, al no

\footnotetext{
13 Ferrándiz, 2014.
} 
querer dejar al resto de la familia atrás, Matilde, decidió reǵresar con sus padres a Castuera, convencida de que en el pueblo no les pasaría nada. Matilde fue detenida, ejecutada extrajudicialmente y su cuerpo enterrado en una fosa común en mayo de 1939. Antonio pasó casi una vida entera en el exilio, reǵresando a España tres años antes de la muerte del dictador, en 1972. La familia de Aurora nunca recuperaría los restos de Matilde.

Impulsada por la incertidumbre todavía existente en torno al paradero de Matilde en la primera década del siǵlo XXI, Aurora se unió a AMECADEC, la asociación para la recuperación de la memoria histórica creada en Castuera en el año 2006, con la esperanza de hallar el cadáver de su madre. Entre 2006 y 2010, con ayuda de este colectivo de familiares y activistas de la memoria, un equipo de arqueólogos prospectó el lugar en el que, según presuntos testigos de la ejecución, se encontraban los restos de Matilde. Tras una primera intervención fallida, el equipo dirigido por Laura Muñoz Encinar realizó un segundo sondeo de una zona adyacente en enero de 2011, durante la misma campaña de localización que estableció la existencia de las Fosas 1 y 3 . Una vez más, no se encontró ningún rastro de los restos de la maestra, exacerbando el desconcierto que había imperado durante décadas sobre su destino final. Las dos exploraciones del terreno situado en la parte delantera del cementerio donde Matilde fue vista con vida por última vez, no constituyeron, sin embargoo, ni el principio ni el final de la búsqueda iniciada por Aurora. Durante el proceso de exhumación de las Fosas 1 y 3, Aurora nos habló de una compleja historia familiar llena de interrogantes, así como de las estrategias de las que ella misma se había valido para darle sentido. Sus narraciones convertían así el escenario de la excavación y el espacio íntimo de su hogar en lo que el antropólogo social Francisco Ferrándiz ha definido como lugares de «legitimación pública» al calor de una «comunidad solidaria de escucha» ${ }^{14}$ surgida en el transcurso de conversaciones informales, diálogos improvisados y entrevistas estructuradas $^{15}$.

En uno de nuestros primeros encuentros, Aurora nos contó que, hasta 2002, su madre fue para ella «su gran desconocida». Hasta ese momento, los detalles

14 Ferrándiz, 2014, p. 122.

15 Como Ferrándiz también observa, estos protocolos han ido surǵiendo de manera paulatina conforme la práctica de las exhumaciones se ha ido desarrollando. Poco a poco se han incorporando nuevas metodologías aplicadas a la recogida de testimonios, que tienen en cuenta tanto los modos de registrar las historias compartidas con el investigador como el lugar y la situación en la que se transmiten (Ferrándiz, 2014, p. 122). El registro de fuentes orales en Extremadura se realizó mediante la colaboración entre historiadores, arqueóloǵos y antropólogos forenses y sociales en el diseño de las preguntas. Asimismo, la grabación de entrevistas se hizo en formato de audio, y en ocasiones, con el consentimiento de la persona, también en formato de video, en lugares elegidos por nuestros interlocutores para testimoniar. 
sobre quién era y cómo murió Matilde se habían manifestado en la vida de Aurora de manera entrecortada, como una imagen difusa oculta tras silencios desgarradores, gestos amargoos y relatos imprecisos. Asimismo, en su testimonio, Aurora entrelazaba la ausencia de Matilde -y también la de Antonio- con la experiencia más amplia de sufrimiento que afectó a toda la familia. Su relato ejemplificaba el carácter inteǵrado de la represión franquista, la cual, como explican algunos autores ${ }^{16}$, comprendió no solo una dimensión física sino también una vertiente cultural y socioeconómica. Citando uno de sus recuerdos más tempranos, Aurora rememoraba el sentimiento de exclusión y miedo que la familia había experimentado tras su llegada a Castuera. "Éramos unos apestados» expresaba por ejemplo al referirse a la manera en que la familia había sido humillada durante los primeros días después del final de la guerra. A la ejecución de Matilde y al exilio de Antonio siguieron la incautación de bienes y propiedades de la familia, su acoso y viǵilancia, la ocultación del cuerpo sin vida de Matilde y la prohibición del duelo por su muerte ${ }^{17}$. En una sociedad de posguerra en la que, como describen alǵunos historiadores, la «prioridad absoluta» del incipiente gobierno franquista fue la de acabar con cualquier rastro de los vencidos ${ }^{18}$ y la de expulsarlos tanto simbólica como realmente «del cuerpo social e identitario de la nación» ${ }^{19}$, muchas personas que sufrieron la represión optaron por silenciar toda experiencia pasada de violencia, embarcándose en un largó «exilio interior» ${ }^{20}$. La familia de Aurora entró a formar parte de lo que el antropólogo Ignacio Fernández de Mata ha señalado como una «comunidad de dolor» ${ }^{21}$ subalternizada en la que las historias de las personas represaliadas por el franquismo se tornaron relatos impronunciables.

Los entresijos de lo acontecido a Matilde y Antonio llegaron a Aurora y a sus hermanas a través de los «llantos» $\mathrm{y}$ «susurros» ${ }^{22}$ que a menudo invadían el interior de su hogar. En nuestras charlas, Aurora evocaba el silencio que siempre rodeó la identidad de su madre, a quien todos tenían presente, pero cuya memoria nadie en la familia se atrevía a invocar. En casa, el nombre de

\footnotetext{
${ }^{16}$ Hernández Burgos y Redondo Cardeñoso, 2011.

17 Las conmemoraciones oficiales en torno a los llamados «caídos por Dios y por España» del Movimiento, que constituyeron el fundamento de la política de memoria y reparación del franquismo, dejaron clara la exclusión de los que sufrieron la derrota de todo ritual estatal. Dicha estrategia conmemorativa unida al resarcimiento único de las víctimas de la violencia republicana contribuyó a deslegitimar la experiencia de las familias de los vencidos, cerrando la puerta a cualquier expresión familiar o manifestación pública del duelo por los represaliados del franquismo. Para un estudio detallado de los nuevos ritos franquistas ver Box, 2010.

18 Casanova et al., 2004, p. 19.

19 Ledesma y Rodrigo, 2006, p. 238.

${ }^{20}$ Molinero, 2003, p. 29.

${ }^{21}$ Fernández de Mata, 2006.

22 Ferrándiz, 2008.
} 
Matilde solo era pronunciado para referirse a la hermana mayor de Aurora, quien heredó el nombre de su madre al nacer. Por otra parte, la prudencia y el disimulo también formaron parte del recuerdo de Antonio, cuyas cartas desde Marruecos nunca dejaban entrever los motivos de su marcha y de su separación de la familia. El silencio también envolvió las preguntas que Aurora hacía a sus tías -y más tarde a su padre, con quien se volvió a encontrar en Marruecos en 1954- sobre el paradero de Matilde. Cuando Aurora pedía a las hermanas de su madre saber dónde estaba o qué le había ocurrido a Matilde, éstas a menudo la mandaban callar, con lágrimas en los ojos, repitiendo afligidas «las niñas no preguntan, las niñas se callan». Las lágrimas y las palabras de sus tías desvelaban la temerosa inquietud provocada por la reminiscencia del trágico final que aconteció a su hermana. La tristeza que emanaba de la expresión de sus rostros, del sonido de sus voces y de su silencio obstinado haría comprender a Aurora que algo siniestro le había ocurrido a su madre. Estas formas de comunicación afectiva -que transmiten significados traumáticos mediante lenguajes corporales y locuciones verbales que rebasan la barrera del silencio ${ }^{23}$ - dan pie a la pulsión de muchos familiares por aprehender los trazos de un pasado elusivo. Como Aurora, alǵunas personas que entrevistamos durante nuestra investigación en campo afirmaban haber intuido siempre el amargo sino de sus familiares represaliados, a pesar de que nadie en casa les hubiese relatado sus historias de muerte y desaparición.

Con el paso del tiempo, el desasosiego que poco a poco había quebrado la trama de silencios familiares generó para muchos descendientes un deseo latente por conocer la suerte de sus allegados. Ya desde muy joven, Aurora emprendería un recorrido por los retales de su memoria, los recuerdos de algunos parientes y otros habitantes de Castuera y los objetos y documentos que otras personas le facilitaron con el fin de saber qué le había sucedido a Matilde. A través de una prima más mayor, Aurora supo que a su madre la habían ejecutado junto a seis personas más y que uno de los tíos de Aurora había intentado reclamar sin éxito el cadáver de Matilde dos días después de su ejecución. Otras personas le hablaron de cómo sus tías presenciaron el momento en el que un grupo de hombres se llevaba a Matilde camino del cementerio para ser vejada y ejecutada, sin poder hacer nada para evitarlo. También hubo testigos que compartieron con ella los detalles más cruentos de la masacre. En 2002, ante la escasa y dispersa información a la que había podido acceder hasta esa fecha y decida a resolver las lagunas y omisiones que todavía marcaban la biografía de Matilde, Aurora se lanzó a explorar otras fuentes materiales en busca de nuevas evidencias sobre el pasado de

${ }^{23}$ Para un análisis sobre la transmisión afectiva de la memoria traumática entre diferentes generaciones ver los trabajos de Cho, 2008; Hirsch, 2012. 
su madre. Como en el caso de otras familias, Aurora buscó el rastro de Matilde en archivos oficiales y colecciones privadas de documentos históricos, fotografías, cartas, recortes de prensa y enseres vinculados a la vida y muerte de su familiar. Frente al silencio dominante y «el caos de emociones» ${ }^{24}$ que la represión franquista trajo a su vida, Aurora esperaba encontrar en algunas de estas fuentes un soporte a partir del cual concebir una historia familiar inasible.

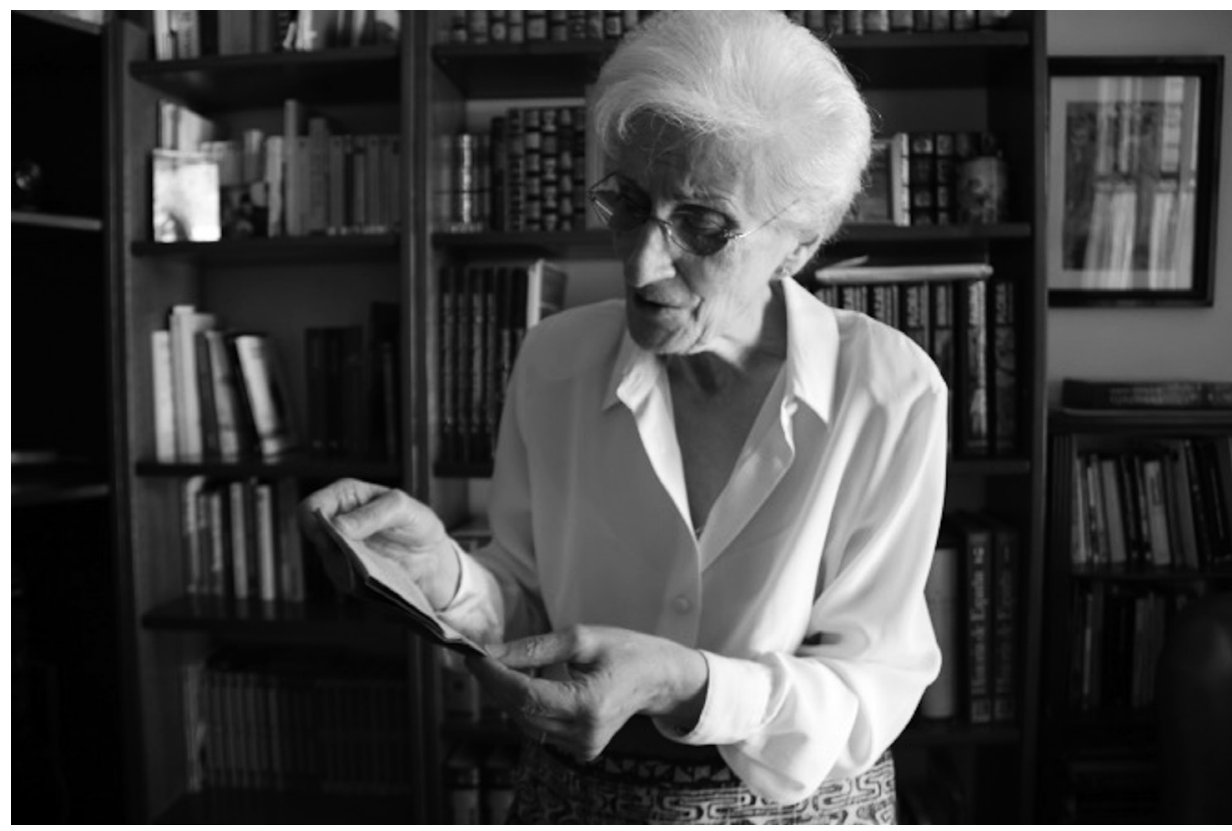

Figura 2. Testimoniar más allá de la fosa común, Castuera, 2011. Imagen de la autora.

La escritora Marianne Hirsch ha descrito la articulación del relato familiar mediante los rastros que se conservan de episodios de violencia extrema, experimentados indirectamente, como un trabajo de "posmemoria». Refriéndose a la manera en que las segundas generaciones de descendientes de la Shoah conectan con la experiencia traumática de sus padres e intentan construir un recuerdo propio, Hirsch define el surǵimiento de la "posmemoria» como un fenómeno asociado a la ruptura violenta de las líneas de comunicación por las que viajan normalmente la memoria familiar y cultural entre generaciones. Según la autora, la «posmemoria» transforma las historias, las experiencias distantes

${ }^{24}$ Hirsch, 2012, p. 34. 
y los objetos que la violencia no logró destruir en vehículos de transmisión que facilitan la configuración de nuevas narrativas sobre el pasado traumático. Así las producciones culturales y familiares de estas segundas generaciones «surgen de un intento de representar los efectos a largo plazo de convivir con el dolor, la depresión y la disociación de las personas que presenciaron o sobrevivieron un evento traumático masivo ${ }^{25}$. En el caso de Aurora, la búsqueda incesante de la figura de Matilde, que recuerda a veces el empeño con el que Austerlitz, el protagonista de la novela de W. G. Sebald, busca a su propia madre décadas después del Holocausto ${ }^{26}$, la llevó a ensamblar un archivo personal desde el que dar sentido a un pasado convulso. La labor de indagación de Aurora le hizo descubrir las lagunas y las visiones distorsionadas que ofrecen los documentos oficiales aportados por algunos historiadores. En el archivo familiar que Aurora construyó a lo largoo de los años, sin embargó, estos documentos coexistían con otros objetos familiares que reafirmaban la identidad de Matilde en un «mundo de ausencias» ${ }^{27} . \mathrm{Su}$ archivo familiar era un espacio desde el que «afirma[r] la existencia de un pasado ${ }^{28}$-más allá de la historia oficial contada por la dictadura- y desde el que poner en práctica nuevas formas de reconocimiento íntimo y social de la vida y muerte de su madre.

\section{Recomponer la identidad de la persona represaliada en el archivo familiar}

La búsqueda de información en los documentos producidos por la dictadura desveló otros vacíos relacionados con la ejecución y la desaparición de Matilde. En 2002, Aurora viajó a Madrid con una de sus hermanas para buscar a Matilde en los expedientes de la Causa General. Este proceso, instruido por el Fiscal del Tribunal Supremo para documentar los presuntos abusos y crímenes cometidos en la zona republicana durante la guerra, sirvió para alimentar los fines propagandísticos de la dictadura y articular la represión contra los colectivos antifranquistas $^{29}$. Ambas hermanas esperaban que su búsqueda en este registro aportase nuevos indicios sobre la manera en que Matilde desapareció o sobre el lugar de su enterramiento. Durante horas, examinaron las carpetas relacionadas con la provincia de Badajoz, nombre por nombre y ficha por ficha, descubriendo la na-

\footnotetext{
25 Hirsch 2012, p. 34.

${ }^{26}$ Sebald, 2001. Ver también Hirsch, 2012.

${ }^{27}$ Douglas, 2014.

${ }^{28}$ Hirsch, 1997, p. 23.

${ }^{29}$ Para un análisis más amplio sobre este proceso ver Ledesma, 2005; Ledesma y Rodrigo, 2006.
} 
rrativa franquista de los hechos contenida en el Archivo Histórico Nacional. Los documentos pertenecientes a este proceso mostraban la clasificación diligente de sospechosos que las nuevas autoridades llevaron a cabo después de la guerra: a través de la redacción de informes que circulaban entre confidentes locales y el fiscal general, los documentos confiscados a diversas organizaciones de izquierda o la delación. Sin embarǵo, una vez más, las hermanas no encontraron ningún rastro de Matilde. La imposibilidad de navegar los papeles de la Causa General, compuesta de más de 4000 cajas, así como de intentar abordar otros complicados depósitos oficiales, impulsó a Aurora a cooperar con historiadores y funcionarios de los juzǵados de la región para obtener algún indicio de la historia de represión de su familia.

Numerosos historiadores, activistas y familiares han constatado en los últimos años las dificultades que existen para investigar los archivos de la represión franquista, debido a las pésimas condiciones en la que se encuentran alǵunos legajos, la falta de acceso a muchas colecciones o la ausencia de documentación ${ }^{30}$. Ante esta situación, Aurora solicitó la ayuda de Antonio López Rodríguez y otros historiadores de la región como Julián Chaves Palacios para navegar los contenidos de este complejo laberinto archivístico. Ambos le proporcionaron información sobre la trayectoria de su padre hacia el exilio, así como el expediente de depuración, mediante el cual Matilde sería destituida de su cargo como maestra en Daimiel. De la mano del secretario del juzǵado de instrucción de Castuera recibió, además, las partidas de nacimiento y defunción de su madre. Documentos, en especial este último, que Aurora había buscado durante toda la vida. El estudio cuidadoso de estos registros evidenciaba, sin embargo -como señala Laura Muñoz Encinar en este número- las tretas burocráticas de las que el incipiente gobierno franquista se valió para encubrir las huellas del crimen. En una de las entrevistas realizadas en su casa, Aurora señalaba que mientras el certificado de defunción establecía que su madre había muerto «como consecuencia de la Guerra Civil» el 30 de marzo de 1939, el acta de depuración, que Matilde había firmado el 9 de abril de ese mismo año demostraba que aun seguía viva días más tarde. Por otra parte, detalles como la detención abrupta de Matilde, su ejecución extrajudicial o los eventos que condujeron a su muerte no figuraban en la partida de defunción, la cual había sido completada y firmada en 1942, tres años después de su asesinato. Además, como observa Muñoz Encinar, en 1946, un juez militar concedió la libertad a Matilde, a pesar de que ésta había sido ejecutada siete años antes.

\footnotetext{
${ }^{30}$ Para un estado de la cuestión consultar González Quintana et al., 2019; Molinero, 2011; Espinosa Maestre, 2009; Amnistía International, 2006.
} 


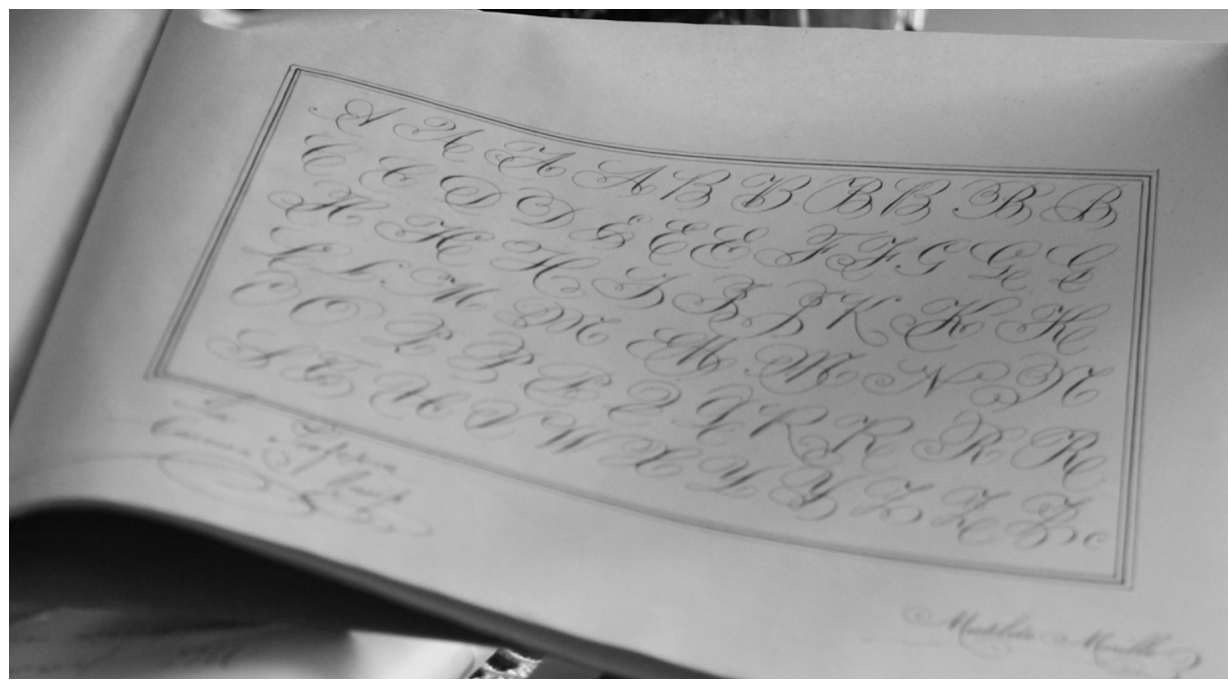

Figura 3. Libro de caligrafía, Castuera, 2011. Imagen de la autora.

La colaboración con historiadores y otros profesionales dedicados al análisis de estas fuentes generó en Aurora un conocimiento íntimo de las anotaciones enǵañosas, así como de la política de ocultación que caracterizó la estrategia represiva del Régimen. A lo largo de nuestra conversación, Aurora reconocía de manera reiterada el carácter fraudulento de estos registros documentales, expresando el fuerte sentimiento de desconfianza y rechazo que provocaban en ella. Así, interpretaba los detalles tergiversados de la muerte de Matilde y la carencia de otros datos oficiales con respecto a lo que verdaderamente ocurrió, como una manera de negar la identidad y existencia de su madre en los archivos del Estado. Resistiendo la realidad antagónica que presentaban estas fuentes, Aurora dedicó tiempo y esfuerzo a ubicar otros objetos que pertenecieron a Matilde para crear nuevos apuntes biográficos sobre su persona y establecer un relato propio sobre su muerte. El libro de caligrafía que Matilde utilizó cuando iba a la escuela, los libros de poemas de sus autores favoritos o las dos únicas fotografías que de ella quedaban se convertían así en puntos mediante los que conectar y contrastar sucesos y experiencias difusas. Marianne Hirsch explica que la relación de la «posmemoria» con el pasado «está mediada no tanto por la rememoración sino por el esfuerzo imaǵinativo, la proyección y la creación» ${ }^{31}$. Mediante el repertorio de documentos oficiales y objetos personales relacionados con Matilde, Aurora

${ }^{31}$ Hirsch, 2012, p. 5. 


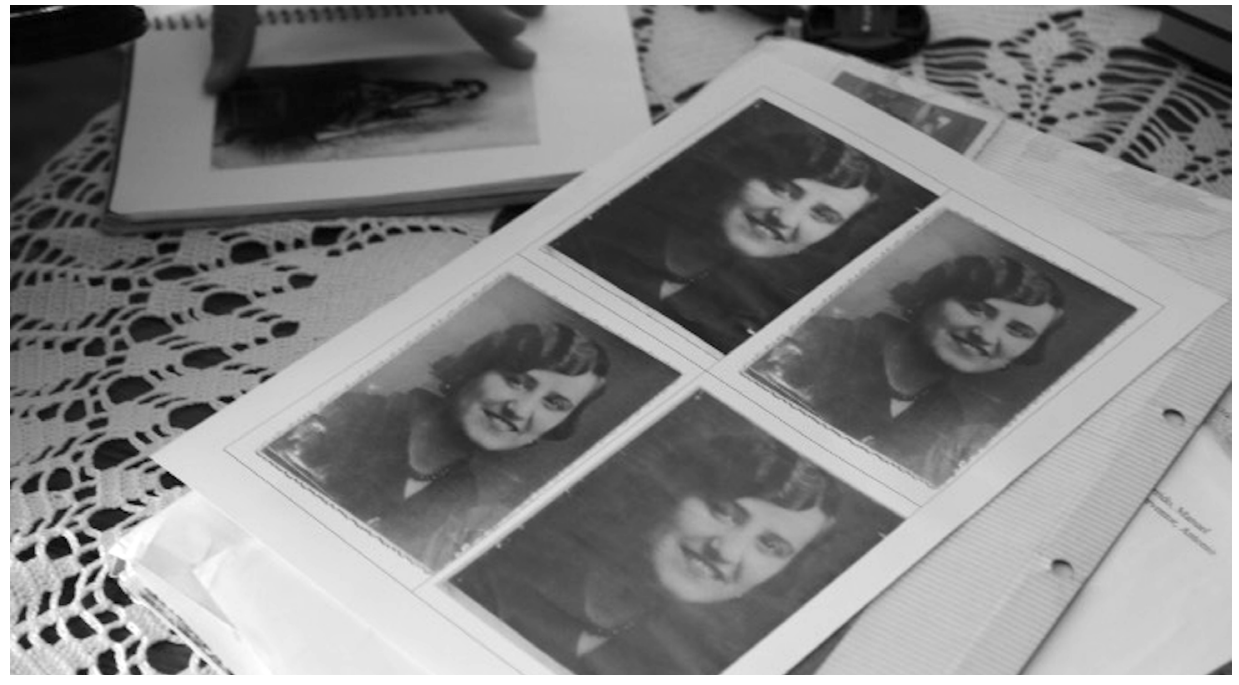

Figura 4. Fotografías de Matilde, Castuera, 2011. Imagen de la autora.

imaginaba los excesos y la crueldad del régimen represivo a la vez que creaba nuevos significados sobre la historia de vida y la subjetividad de su madre, de la que guardaba escasos recuerdos.

Los objetos personales de Matilde y algunos de los relatos asociados a ellos permitían a Aurora vislumbrar la personalidad, las inquietudes, los gustos o las costumbres de su madre. Como los objetos recuperados en las exhumaciones de Bosnia-Herzegovina citados al principio de este artículo, los enseres de Matilde ofrecían a Aurora destellos de su identidad. A diferencia del ejemplo analizado por Sarah E. Wagner, sin embargoo, en el proceso de identificación llevado a cabo por Aurora primaba la alusión a rasgoos imaginados sobre los que poco se había elaborado durante su infancia y adolescencia ${ }^{32}$. Objetos biográficos como el libro de caligrafía de Matilde mostraban a Aurora un pedazo de la infancia y adolescencia su madre, haciendo referencia a la escuela a la que fue y a su vida de estudiante. Aurora admiraba la destreza de su trazo y su letra perfecta, que reconocía no solo en el libro de escritura sino también en los documentos que, como el expediente de depuración, Matilde había completado días antes de morir. Otros objetos como las obras de poesía preferidas de Matilde, que la familia había conseguido rescatar tras la destrucción y expropiación de muchas de sus pertenencias, acercaban a Aurora

32 Para un análisis sobre esta temática en otros contextos de exhumación en España ver Renshaw, 2011, pp. 131-136. 
al mundo interior de su madre. Recitando los mismos versos del libro de Heinrich Heine que su madre había leído en el pasado, Aurora sentía que la distancia con Matilde se estrechaba: «a mí me hace mucha ilusión leerlo, porque mi madre lo leyó y ella también lo cogió como tu y como yo». Su contenido y también su tacto convertían la materialidad de estos libros en un punto de convergencia entre dos generaciones cruentamente separadas por la violencia de posguerra.

Confrontada por la carencia de experiencias compartidas, las pertenencias de Matilde ofrecían a Aurora una vía de comunicación con un pasado irrecuperable. Junto a los libros, las únicas imágenes que Aurora pudo localizar de Matilde a lo largo de las últimas décadas representaban el testimonio más fehaciente de su existencia. Señalando una de las instantáneas, que Aurora había encontrado a los 20 años en el archivo de un fotógrafo local que capturó a Matilde y a sus compañeras universitarias el día de su graduación, Aurora resaltaba el valor probatorio de la fotografía: «esta fotografía es prueba de que mi madre existió, aunque quisieran borrarla, ella existió». En este sentido, y tal y como lo define la antropóloga social y arqueóloga Layla Renshaw en su estudio sobre exhumaciones en España, la fotografía del familiar represaliado se convierte en «una materialización tanǵible e irrefutable» ${ }^{33} \mathrm{de}$ la persona desparecida. Ante la ausencia del cuerpo, la imagen reafirma el vínculo afectivo entre el superviviente y la persona fotografiada que ya no está ${ }^{34}$. Su presencia en lugares visibles de la casa o de la comunidad además asevera y legitima el lugar de la persona desaparecida en el entorno social del superviviente ${ }^{35}$. Aurora haría decenas de copias de la fotografía para tenerla en su casa y compartirla con sus hermanas, tías y amigas. Otras copias irían a parar a los archivos emergentes de investigadores y actores institucionales, con el objetivo de movilizar la búsqueda de su madre en un contexto político saturado por décadas de impunidad. Finalmente, la misma fotografía acabaría como referente de Matilde dentro del cementerio municipal del pueblo. Colocada en la parte superior de un monolito construido a su memoria, la fotografía de Matilde marca el lugar donde fue ejecutada y presuntamente enterrada, pero donde su cadáver nunca fue encontrado.

En su etnografía sobre la vida social de las fotografías de las víctimas de la represión franquista, el antropólogo social y visual Jorge Moreno Andrés habla de los conjuntos de objetos e imágenes que muchas familias conservaron en sus casas como «tesoros» del difunto represaliado tras el final de la contienda. Estos repertorios, a los que el autor se refiere como «altares profanos», siguiendo la

\footnotetext{
33 Renshaw, 2011, p. 134.

${ }^{34}$ Un vínculo que Ronald Barthes identificó como el «cordón umbilical» de luz que «une el cuerpo de la cosa fotografiada a [la] mirada» (Barthes, 1990, pp. 143). Una reflexión más amplia sobre el papel de la fotografía en el recuerdo del familiar represaliado en Moreno Andrés, 2018.

35 Renshaw, 2011.
} 


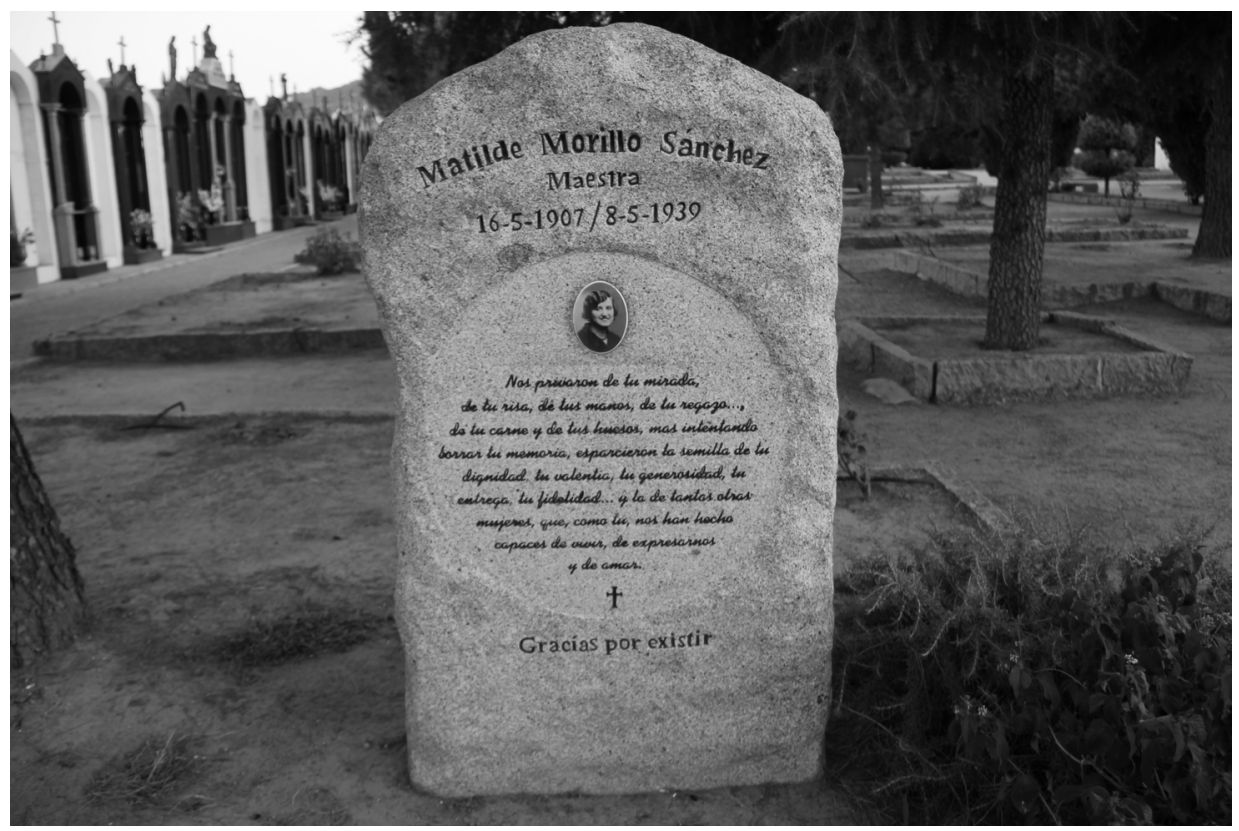

Figura 5. Monolito con la fotografía de Matilde Morillo Sánchez, Castuera, 2011. Imagen de la autora.

denominación propuesta por el antropólogo Julián López García, ayudaron a muchos familiares a «construir la imagen del ser querido» frente a la ausencia de su cuerpo durante la posguerra. Así, tocar y guardar estos objetos en cajas y otros lugares se convertía también en «una metáfora de su sepultura». De este ejemplo se desplieǵa el «valor sentimental» ${ }^{36}$ que estos acervos de la memoria adquirieron en la intimidad de los hogares afectados por la represión franquista en los años después del conflicto. En la actualidad, colecciones como la de Aurora, a las que nos referimos como archivos familiares, entrañan estas formas de reconocimiento personal que Jorge Moreno Andrés identifica en su trabajo antropológico. A su vez, sin embargó, también materializan el empeño familiar dirigido a la obtención de un reconocimiento público -o mutuo ${ }^{37}$ - de estas historias de represión silenciadas. Por una parte, estos conjuntos que contienen objetos y referencias personales, así como documentos extraídos de fuentes oficiales, facilitan la transmisión de un relato ensamblado, aunque todavía impreciso, a otras generaciones de hijos, nietos y sobrinos. En el contexto de la exhumación, además, el mismo

36 Todas las citas en Moreno Andrés, 2018, p. 47.

${ }^{37}$ Ricoeur, 2005. 
repertorio deviene un foco de intercambios intra-generacionales ${ }^{38}$-con investigadores, voluntarios, representantes políticos y otras personas interesadas- mediante el cual la historia familiar y la identidad de la víctima entran a formar parte del imaǵinario colectivo sobre la represión. Una mirada a estos archivos personales de la represión revela el rastro de un esfuerzo personal infatigable dirigido a articular una historia familiar quebrantada, entrelazada en todo momento con la historia de violencia que marcó el devenir de todo un país.

\section{Conclusiones}

El contexto actual de búsqueda, localización y exhumación de los cadáveres de las víctimas de la represión franquista ha dado lugar a nuevas formas de articulación del pasado traumático en el país. En estos procesos, diferentes saberes científicos y familiares a menudo convergen con el fin de facilitar la recuperación e identificación de los restos encontrados en las fosas comunes y esclarecer la historia de los crímenes cometidos y de sus víctimas. Como hemos visto en el ejemplo de Castuera, a pesar de que los equipos forenses no siempre han logrado localizar y exhumar con éxito los cadáveres de las personas represaliadas -debido a las estrategias de encubrimiento utilizadas por los perpetradores- el proceso de exhumación sigue siendo un importante punto de acceso a la experiencia de represión de las familias de los vencidos. El espacio de la fosa común y los lugares que a él se vinculan, se convierten en escenarios públicos desde los que visibilizar los estraǵos que el silencio causó en la memoria de los descendientes de las víctimas. Así como las búsquedas incesantes que muchos familiares emprendieron en el intento de revertir sus efectos.

En casos como el de Aurora sus pesquisas la llevaron a explorar los fraǵmentos esparcidos de su historia familiar en recuerdos aprendidos, documentos oficiales y objetos personales. Aurora compuso un archivo familiar desde el que reactivar la tenue estela que dejó Matilde, confrontando las ausencias e incongruencias contenidas en los papeles del Régimen sobre la muerte de Matilde. Los enseres y las fotografías de su madre, además, desencadenaron otros significados, emociones y sentimientos desde los que reclamar la existencia e identidad de Matilde, a pesar de que su trazo continuara siendo borroso. La carga afectiva y la materialidad de estos objetos afianzaron el lugar de Matilde en la vida de Aurora y en la de su familia, reafirmando su historicidad y la de los eventos represivos acontecidos. Estos archivos familiares son la huella de un proceso de búsqueda y comprensión de la historia que marcó la vida de descendientes como Aurora, desde el momento de la

${ }^{38}$ Hirsch, 2012. 
desaparición de sus familiares hasta el momento de su propia muerte. La huella de un proceso pertinaz por restituir la memoria familiar en los anales de una historia común marcada, todavía hoy, por la impunidad de los crímenes del franquismo.

\section{Bibliografía}

Amnistía International, «Víctimas de la Guerra Civil y el Franquismo: el desastre de los archivos, la privatización de la verdad», Madrid, Amnistía Internacional, 30 de marzo de 2006.

Barthes, Roland, La cámara lúcida: Nota sobre la fotografía, Barcelona, Ediciones Paidós, 1990.

Box, Zira, España año cero: la construcción simbólica del franquismo, Madrid, Alianza Editorial, 2010.

Casanova, Julián, Francisco Espinosa, Contxita Mir, y Francisco Moreno Gómez, Morir, matar, sobrevivir: la violencia en la dictadura de Franco, Barcelona, Grupo Planeta (GBS), 2004

Cho, Grace M., Haunting the Korean Diaspora: Shame, Secrecy, and the Forgotten War, Minneapolis, University of Minnesota Press, 2008.

Delacroix, Dorothée y Anne Marie Losonczy, «Exhumaciones inacabadas. Equivocaciones y contingencias de la búsqueda de cuerpos en contextos posconflicto latinoamericanos y europeos», Nuevos mundos, mundos nuevos, https://journals. openedition.org/nuevomundo/83589?lang=es [consultado el 02/06/2021].

Douglas, Lee, "Mass graves gone missing: Producing knowledge in a world of absence», Culture and History Digital Journal, 3.2, 2014, pp. 1-12.

Espinosa Maestre, Francisco, «Informe sobre la represión franquista. Estado de la cuestión», en Mirta Núñez Díaz-Balart (ed.), La gran represión. Los años de plomo del franquismo, Barcelona, Flor del Viento, 2009, pp. 433-444.

Etxeberría, Francisco, y Queralt Solé, «Fosas comunes de la Guerra Civil en el siǵlo Xxi: antecedentes, interdisciplinariedad y legislación», Historia Contemporánea, 60, 2019, pp. 401-438.

Fernández de Mata, Ignacio, «La memoria y la escucha, la ruptura del mundo y el conflicto de memorias», Hispania Nova. Revista de Historia Contemporánea, 6 2006, pp. 1-22.

Ferrándiz, Francisco, «Cries and Whispers: Exhuming and Narrating Defeat in Spain Today», Journal of Spanish Cultural Studies, 9.2, 2008, pp. 177-192.

Ferrándiz, Francisco, El pasado bajo tierra: exhumaciones contemporáneas de la Guerra Civil, Barcelona, Anthropos, 2014.

González Quintana, Antonio, Sergio Gálvez Biesca, y Luis Castro Berrojo, El acceso a los archivos en España, Madrid, Fundación Largo Caballero/Fundación 1 de Mayo, 2019.

Hernández Burgos, Claudio, y Miguel Ángel Redondo Cardeñoso, «Más allá de las tapias de los cementerios: la represión cultural y socioeconómica en la España franquista (1936-1951)», Cuadernos de Historia Contemporánea, 33, 2011, pp. 7193. doi: https://doi.org/10.5209/rev_CHCO.2011.v33.36666. 
Hirsch, Marianne, Family frames: photography, narrative, and postmemory, Cambridge, Mass./London, Harvard University Press, 1997.

Hirsch, Marianne, The generation of postmemory: writing and visual culture after the Holocaust, New York, N.Y./Chichester, Columbia University Press, 2012.

Ledesma, José Luis, «La Causa General: fuente sobre la violencia, la Guerra Civil (y el franquismo)», Spagna Contemporánea, 28, 2005, pp. 203-220.

Ledesma, José Luis, y Javier Rodrigo, «Caídos por España, mártires de la libertad. Víctimas y conmemoración de la Guerra Civil en la España posbélica (1939-2006)», Ayer, 63, 2006, pp. 233-255.

León Cáceres, Guillermo, Antonio D. López Rodríguez, y José Ramón González Cortés, «El campo de concentración de Castuera: del olvido forzado a lugar de memoria y recurso didáctico», Revista de Estudios Extremeños, 67.2, 2011, pp. 527-594.

López Rodríguez, Antonio D., Cruz, bandera y Caudillo: el campo de concentración de Castuera, Badajoz, CEDER-La Serena, 2006.

López Rodríguez, Antonio D., «Del campo de concentración y la prisión al cementerio: breve introducción a la represión franquista en el partido judicial de Castuera», en Laura Muñoz Encinar, Xurxo M. Ayán Vila, y Antonio D. López Rodríguez (eds.), De la ocultación de las fosas a las exhumaciones. La represión franquista en el entorno del Campo de Concentración de Castuera, Extremadura, AMECADEC/ Ministerio de la Presidencia de España/CSIG-INCIPIT, 2013, pp. 41-61.

Molinero, Carme, «Memoria de la represión y olvido del franquismo», Pasajes: Revista de pensamiento contemporáneo, 11, 2003, pp. 25-33.

Molinero, Carme, «El acceso a los archivos y la investigación histórica», Ayer, 81.1, 2011, pp. 285-297.

Moreno Andrés, Jorge, El duelo revelado: la vida social de las fotografías familiares de las víctimas del franquismo, Madrid, Consejo Superior de Investigaciones Científicas, 2018.

Muñoz Encinar, Laura, «Exhumación en el cementerio de Castuera. Campaña 2011», Laura Muñoz Encinar, Xurxo M. Ayán Vila, y Antonio D. López Rodríguez (eds.), De la ocultación de las fosas a las exhumaciones. La represión franquista en el entorno del Campo de Concentración de Castuera, Extremadura, AMECADEC/ Ministerio de la Presidencia de España/CSIC-INCIPIT, 2013, pp. 62-115.

Renshaw, Layla, Exhuming loss: memory, materiality and mass graves of the Spanish Civil War, Walnut Creek, Calif., Left Coast, 2011, pp. 131-136.

Ricoeur, Paul, Caminos del reconocimiento, Madrid, Trotta Editorial, 2005.

Ríos, Luis, «Identificación en fosas comunes de la Guerra Givil: limitaciones y posibilidades a partir del caso de Burgos», Boletín Galego de Medicina Legal e Forense, 18, 2012, pp. 125-141.

Rodrigo, Javier, Hasta la raíz: Violencia durante la Guerra Civil y la dictadura franquista. Madrid, Alianza, 2008.

Sebald, W. G., Austerlitz, London, Penguin Books, 2001.

Wagner, Sarah E., To know where he lies: DNA technology and the search for Srebrenica's missing, Berkeley, Calif./London, University of California Press, 2008. 